\title{
The development of the mammalian dentition as a complex adap- tive system
}

\author{
Alan H. Brook ${ }^{1,2}$, Toby E. Hughes ${ }^{1}$, Grant C. Townsend ${ }^{1}$, Richard N. Smith ${ }^{3}$ and Matthew D. Brook \\ O'Donnell \\ ${ }^{1}$ School of Dentistry, University of Adelaide, 2 School of Dentistry, Queen Mary University of London \\ ${ }^{3}$ Dental School, University of Liverpool, ${ }^{4}$ Annenberg School for Communication Studies, University of Pennsylva- \\ nia
}

Keywords: Complex Systems, Networks, Dental Development

ABSTRACT General characteristics of Complex Adaptive Systems include self-adaptation and organisation, emergence, multitasking, robustness, critical phases, diversity and compatibility with such statistical models as Thresholds and Scale Free Networks. The aim was to investigate whether dental development exhibits the general and statistical characteristics of a Complex Adaptive System, by examining data on normal and abnormal dental development. The findings were that self-adaptation and organisation occur while interactions between genes, epigenetic and environmental factors lead to the emergence of cells, tooth germs and mineralised teeth. Multitasking occurs as signalling pathways act simultaneously and reiteratively during initiation and morphogenesis.

Complex Systems are widespread in biological systems and communities. Interacting adaptive entities produce dynamic patterns and structure. In a biological complex adaptive system the interaction of lower level components leads to the emergence of high level phenomena and structures. Such systems have the general characteristics of self-adaptation, self-organisation, emergence, multitasking, robustness, critical phases, diversity and compatibility, with such statistical properties as Thresholds and Scale Free Networks (Barabasi, 2003; Camzine et al., 2003; Mitchell, 2009). The aim of this study was to investigate whether development of the dentition exhibits the general and statistical characteristics of a Complex Adaptive System by examining data on normal and abnormal dental development.

\section{DENTAL DEVELOPMENT}

Key characteristics of dental development are that it is multi-levelled, has multiple interactions, is multi-factorial, is multidimensional and is progressive over time (Brook, 2009). The core compo-
Tooth germs that do not attain a critical threshold during development may undergo apoptosis. Diversity is evident in tooth number, size, shape and mineralisation. Statistical investigation shows that males have significantly larger teeth and higher prevalences of megadontia and supernumerary teeth $(\mathrm{p}<0.05)$, supporting Brook's Threshold Model which is further developed here to include shape. Image Analysis of tooth dimensions showed they followed a Power Law distribution, with the first 8 of 34 factors in upper lateral incisors accounting for $94.4 \%$ of the total variation. In conclusion, the development of the dentition shows the general and statistical characteristics of a Complex Adaptive System.

nents of this process are summarised in Table 1 and are illustrated in Figure 1.

\section{THE DENTITION AS A COMPLEX SYSTEM}

The next step is to examine the components of dental development against the key characteristics of complex systems.

Self-organisation and emergence are evident as tooth germs emerge from molecular level interactions (Lesot and Brook, 2009)and then progressively develop and grow in size and shape until they commence calcification and form mature teeth. The initiation of tooth germs occurs at specific sites within a field and they progress to form different shapes and sizes, so that the calcified macroscopic teeth which emerge are discrete but organised into groups that have different shapes and functions around the dental arch.

Correspondence to:

Alan Brook, School of Dentistry, University of Adelaide, Adelaide, South Australia, 5005

Email: alan.brook@adelaide.edu.au

Telephone: +61 (0)8 83132910 
PROGRESSIVE DEVELOPMENT OF EACH TOOTH

\begin{tabular}{|c|c|c|c|}
\hline $\begin{array}{c}\text { Initiation } \\
\text { (tooth number) }\end{array}$ & $\begin{array}{c}\text { Morphogenesis } \\
\text { (tooth size and shape) }\end{array}$ & $\begin{array}{l}\text { Differentiation } \\
\text { (tooth tissues and } \\
\text { mineralisation) }\end{array}$ & Eruption \\
\hline
\end{tabular}

A. Genetic
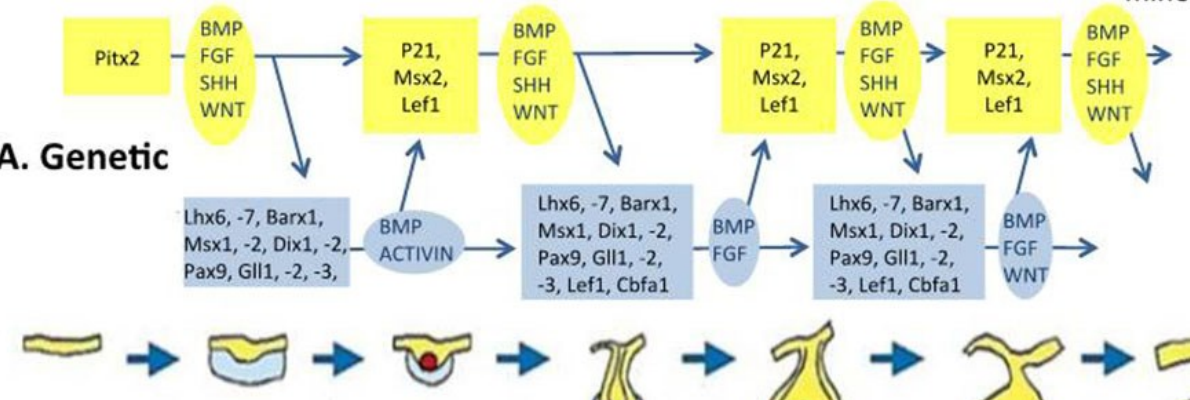

\section{B. Cellular/}

Tissues

\section{Macroscopic Outcome}

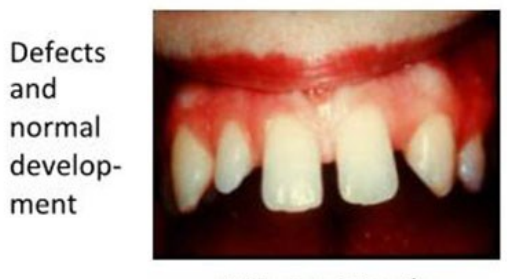

Missing Teeth

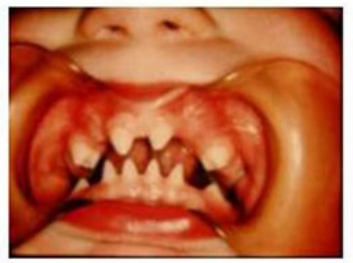

Abnormal Shape

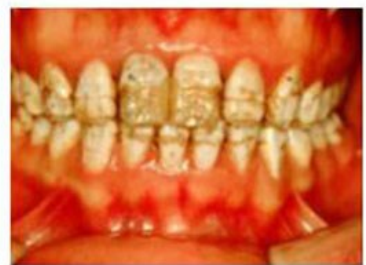

Abnormal Mineralisation

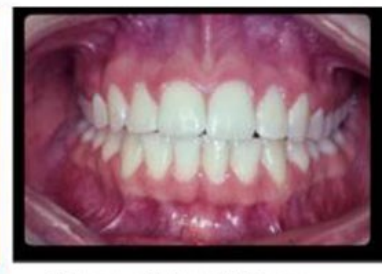

Normal Dentition

Fig. 1. The multilayered developmental process of tooth formation illustrating the molecular changes within the cells and tissues and the macroscopic outcomes (part of figure from http://bite-it.helsinki.fi/).

TABLE 1. The key characteristics and components of dental development

\begin{tabular}{ll}
\hline Characteristic & Components \\
\hline Multilevel & Mature tooth \\
& Cells, tissues, tooth germs \\
& Molecular \\
Multiple interactions & Tooth germ - Tooth germ \\
& Cell - Matrix \\
& Cell - Cell \\
& Gene - Epigenetic - Environment \\
& Gene - Gene \\
Multifactorial & Environmental - local / systemic \\
& Epigenetic - narrow / broad \\
Multidimensional & Over 300 genes \\
& Spacial - x, y, z dimensions \\
Progressive over time & Time \\
& Each dentition \\
& Tooth type / morphogenetic field \\
& Each tooth \\
\hline
\end{tabular}


The outcome is an integrated, balanced, complex system. It is a major characteristic of a complex system that the mature units bear no resemblance to the precursor entities.

Self-Adaptation is demonstrated by the within -species and between-species diversity that is found. In humans, variations in the number, size, shape and mineralisation of teeth occur frequently (Brook et al., 2009; Townsend et al., 2009). Between species variation in these parameters is also extensive (Hillson, 1986). One of the factors to consider is the adaptive interaction that can occur between developing tooth germs, with the timing of development of each being important. Timing is also significant in the critical phases of dental development. For progression from the initial phase to morphogenesis (Fig. 1), transcription factors in the Msx, Dlx and Lhx families are required. The tooth germ may undergo apoptosis if this progress does not occur at this critical time. Similarly, if the matrix proteins are not removed during enamel calcification, defects in mineralisation result.

Robustness in the development of the dentition comes from the satisfactory functioning of the system even in the presence of variations and moderate developmental defects. Mature teeth have some ability to self-repair and continue to develop in response to environmental challenges, a property akin to self-awareness. This robustness is also associated with excess capacity: genes are switched on and off and function reiteratively in multiple tissues; genes can also be up-regulated, down-regulated and, if their function is defective, other genes sometimes function to produce the necessary product; genes in function can be alternatively spliced and the products varied in amount and nature.

Multitasking adds to this robustness as signalling pathways act simultaneously and reiteratively. Similarly, the ameloblasts control the secretion and later removal of the enamel matrix proteins, as well as the deposition of the minerals.

\section{STATISTICAL MODELS}

Based on epidemiological and clinical data, Brook (1984) developed a model to explain the relationship between the prevalence of dental anomalies of number and size. This model is based on a normal distribution on which thresholds are superimposed beyond which microdontia, hypodontia, megadontia and supernumerary teeth occur. Here the model is further developed to include shape (Fig. 2). As tooth size moves closer to the thresholds that determine variation in tooth number, teeth tend to display abnormal shape as well as size. An example is the diminutive perma-

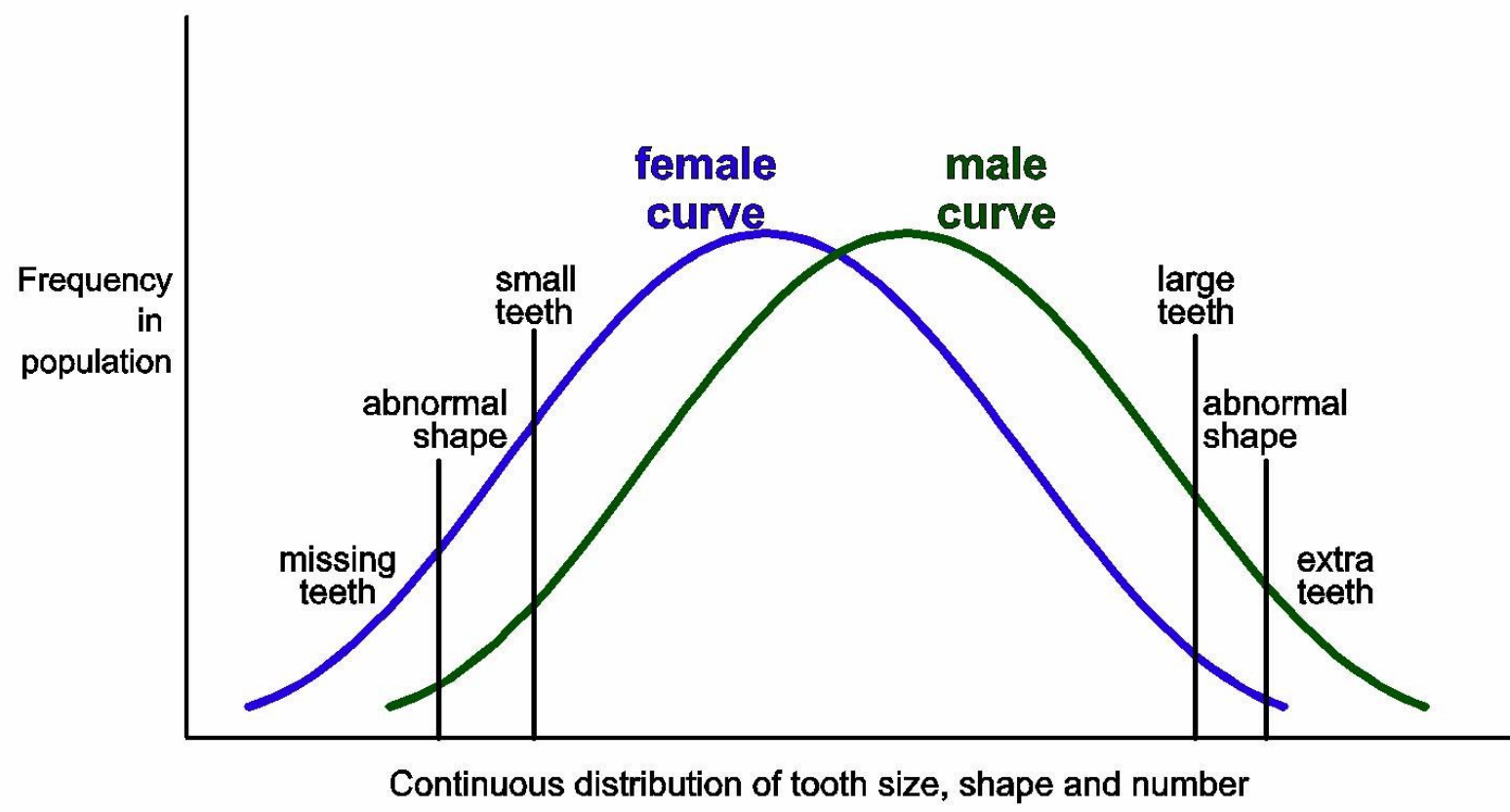

Fig. 2. This development of the Threshold Model of Brook (1984) now incorporates the shape changes seen at the extremes of tooth size. 
nent upper lateral incisor which is often 'pegshaped' as well as being very small. The developmental process underlying these clinical findings and modelling has been elucidated in molecular genetics and histological studies (Brook, 2009; Lesot and Brook, 2009).

The Scale Free Network model reflects findings that when the frequencies of each of the components in some systems are plotted, the result is a Power Law Distribution (Fig. 3).

This distribution occurs when a few components occur with a high frequency and the large majority occur with lower frequency. In a Principal Component Analysis of 34 dimensions in upper incisor teeth, 94 per cent of the total variance was accounted for by 7 dimensions (Khalaf et al., 2009), thereby displaying the properties of a Scale Free Network.

\section{CONCLUSIONS}

The dentition exhibits the characteristics of a Complex Adaptive System, both in development and in its mature form. During evolution it has become adapted to different environments. It serves as a valuable model for investigating how genetic, epigenetic and environmental factors interact during somatic development.

\section{ACKNOWLEDGMENTS}

This project was part of the studies funded by Wellcome Programme Grant 3256.

\section{LITERATURE CITED}

Barabasi AL. 2003. Linked. Plume Books. Penguin Group New York.

Brook AH. 1984. A unifying aetiological explanation for anomalies of tooth number and size in humans. Arch Oral Biol 29:373-378.

Brook AH. 2009. Multilevel complex interactions between genetic, epigenetic and environmental factors in the aetiology of anomalies of dental development. Arch Oral Biol 54:S3-S17.

Brook AH, Griffin RC, Smith R, Townsend GC, Kaur G, Davis GR, Fearne G. 2009. Tooth size patterns in patients with hypodontia and super numerary teeth. Arch Oral Biol 54:S63-S70.

Camazine S, Deneubourg J-L, Franks NR, Sneyd J, Theraula G, Bonabeau E. 2003 Self-Organization in Biological Systems. Princetown, NJ: Princeton

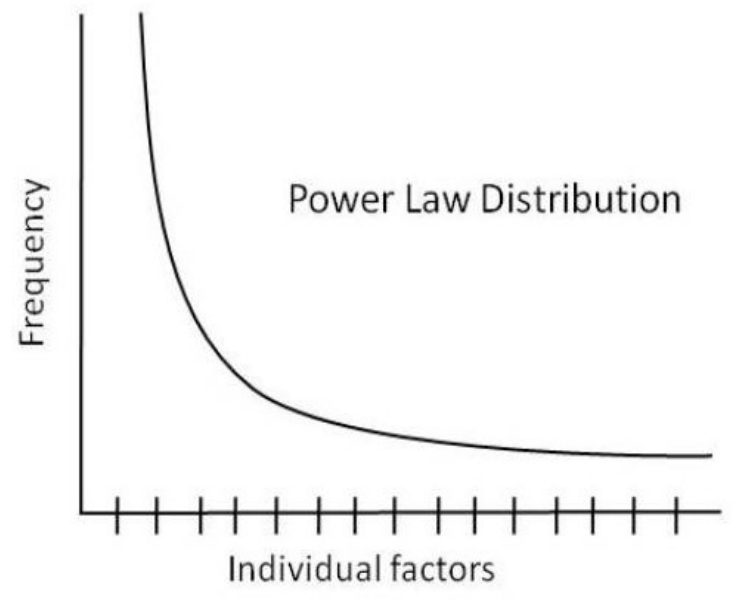

Fig. 3. A typical power law distribution where a few factors occur frequently in a system

University Press.

Hillson S. 1986. Teeth. Cambridge University Press.

Khalaf K, Smith RN, Elcock C, Brook AH. 2009. Multiple crown variables of the upper incisors in patients with supernumerary teeth compared with controls. Arch Oral Biol 54:S71S78.

Lesot H, Brook AH. 2009. Epithelial histogenesis during tooth development. Arch of Oral Biol 54:S25-S33.

Mitchell M. 2009. Complexity. A guided tour. Oxford University Press.

Townsend G, Harris EF, Lesot H, Clauss F, Brook AH. 2009. Morphogenetic fields within the hu man dentition: A new, clinically relevant synthesis of an old concept. Arch Oral Biol 54: S34-S44. 